\title{
Physico-enzymatic production of monoacylglycerols enriched with very-long-chain polyunsaturated fatty acids
}

\author{
Pawongrat, Ratchapol; Xu, Xuebing; H-Kittikun, Aran
}

Published in:

Journal of the Science of Food and Agriculture

Link to article, DOI:

10.1002/jsfa.3081

Publication date:

2008

Document Version

Early version, also known as pre-print

Link back to DTU Orbit

Citation (APA):

Pawongrat, R., Xu, X., \& H-Kittikun, A. (2008). Physico-enzymatic production of monoacylglycerols enriched with very-long-chain polyunsaturated fatty acids. Journal of the Science of Food and Agriculture, 88(2), 256-262. https://doi.org/10.1002/jsfa.3081

\section{General rights}

Copyright and moral rights for the publications made accessible in the public portal are retained by the authors and/or other copyright owners and it is a condition of accessing publications that users recognise and abide by the legal requirements associated with these rights.

- Users may download and print one copy of any publication from the public portal for the purpose of private study or research.

- You may not further distribute the material or use it for any profit-making activity or commercial gain

- You may freely distribute the URL identifying the publication in the public portal 
1 Physicoenzymatic Production of Monoacylglycerols Enriched with Very Long

2 Chain Polyunsaturated Fatty Acids

3

4

5

6 Ratchapol Pawongrat, ${ }^{1}$ Xuebing $\mathrm{Xu}^{{ }^{2 *}}$ and Aran H-Kittikun ${ }^{1}$

$7 \quad{ }^{1}$ Department of Industrial Biotechnology, Faculty of Agro-Industry, Prince of Songkla

8 University, Hat Yai 90112, Thailand.

$9 \quad{ }^{2}$ BioCentrum-DTU, Technical University of Denmark, Building 227, DK-2800 Kgs, 10 Lyngby, Denmark.

11

12 Running title: Production of PUFA monoacylglycerols

*Corresponding author. Tel: +45 4525 7773; fax: +45 45884922

17

E-mail address: xx@biocentrum.dtu.dk

18 


\section{ABSTRACT}

2 Background: Monoacylglycerols (MAG) containing polyunsaturated fatty acids

3 (PUFA), especially, eicosapentaenoic acid (EPA) and docosahexaenoic acid (DHA),

4 have interesting applications. The enzymatic processing of such MAG directly from

5 fish oils is highly interesting integrating the processing of MAG and concentration of

6 EPA and DHA. The aim of this study was then to develop an efficient enzymatic

7 glycerolysis system together with physical fractionation for the production of PUFA-

8 MAG from tuna oil. Results: Novozym 435 was eventually selected after evaluation

9 together with the immobilized Lipase AK in tertiary alcohol based system. A further

10 evaluation of solvent mixtures involving tertiary alcohols was made, taking the

11 consideration of operation easiness. It turned out that a number of mixtures gave 12 similar performances as tert-butanol (TB). Basic reaction parameters were thoroughly evaluated. In the batch reaction system with $\mathrm{TB}$ as solvent, the recommended conditions were: glycerol/tuna oil $4: 1 \mathrm{~mol} / \mathrm{mol}$, TB/tuna oil $2: 1 \mathrm{wt} / \mathrm{wt}, 15 \mathrm{wt} \%$ Novozym 435, and temperature $40{ }^{\circ} \mathrm{C}$. Under these conditions, the yield of MAG was up to $90 \%$ after $3 \mathrm{~h}$ incubation. Crude MAG from the production was fractionated to produce MAG with higher EPA and DHA content. Using acetone as solvent at $0{ }^{\circ} \mathrm{C}$ led to ca. 50\% yield of MAG but contained EPA and DHA up to $71 \%$ in comparison with ca. $30 \%$ in tuna oil. Conclusion: Potentially practical process steps have been developed for the production of MAG containing high content of EPA and DHA from natural fish oils with high efficiency and simplicity.

Keywords: Monoacylglycerols, glycerolysis, fractionation, polyunsaturated fatty acid (PUFA), Novozym 435, tuna oil 


\section{INTRODUCTION}

Monoacylglycerols (MAG) or mixtures with diacylglycerols (DAG) account for approximately $75 \%$ of the emulsifier production and have applications in different fields. ${ }^{1-3}$ In the food industry, MAG are widely used in bakery products, margarines, dairy products, and confectionary because of their emulsifying, stabilizing, and conditioning properties. They are also important in cosmetic and pharmaceutical industries as drug carriers and for consistency improvements in creams and lotions. Commercial food MAG are manufactured by chemical glycerolysis of fats and oils. High temperature $\left(220-250^{\circ} \mathrm{C}\right)$ and inorganic alkaline catalysts are used to accelerate the reactions. These chemical and physical processes are not suitable for heatsensitive oils and fats because of potential deleterious effects on nutritional and biological properties.

Lipase-catalyzed glycerolysis of fats and oils at atmospheric pressure and low temperature has attracted interest in both academia and industry as a practical alternative to chemical methods in the production of commercial MAG. Several glycerolysis systems have been investigated with or without organic solvents, with immobilized or non-immobilized enzymes, and in microemulsion or other media. ${ }^{3-4}$

Glycerolysis system with an immobilized lipase as catalyst is a three-phase system: a hydrophobic oil phase, a hydrophilic glycerol phase, and a solid enzyme phase. Because of the more hydrophilic characteristics of the enzyme, glycerol often binds to enzyme particles so that the access of oil molecules to the enzyme is difficult. The mass transfer of glycerol is also limited. Thus the reaction efficiency is usually low even though the efficiency can be improved through optimization in a narrow range. It is reported that glycerol can be immobilized on silica gel so as to overcome 
1 these problems. ${ }^{1,4}$ The improvement is only minor, however, not to say difficulties in

2 practical operations. Therefore, a solvent medium is actually an important solution to

3 improve the homogeneity of the system.

A single solvent that can dissolve oil and glycerol in a homogeneous system is actually very difficult to find. The hydrocarbon solvents were generally impossible for this purpose. After evaluation, a few alcohols with more than five carbons can be considered since they contain a polar hydroxyl group and a nonpolar carbon chain. However, alcohols are naturally reaction competitors to glycerol, especially the primary alcohols. From the study of Damstrup et $a l^{2}$ and Yang et al. ${ }^{5}$, the use of tertiary alcohols is possible and does not involve in reactions with fatty acids, most likely due to the tertiary structure of the alcohols, which exerts strong steric hindrance to the enzyme in the system. Therefore, TB or tert-pentanol (TP) is promising for the glycerolysis system. Higher yield of MAG has been achieved with tertiary alcohols in the glycerolysis system ${ }^{2,5}$.

Omega-3 PUFA have received much attention in recent years because of the health benefits they offer, including reduced risk of coronary disease, prevention of certain cancers, and improved immune function. ${ }^{6,7}$ Omega-3 PUFA-containing MAG are interesting for many potential uses or applications in food, drug, or cosmetic production. Their MAG forms may offer new possibilities in different applications. We have intended to synthesize MAG from fish oil with higher content of omega-3 PUFA through alcoholysis of fish oil with 1,3-specific lipases. ${ }^{8,9}$ The reaction strategy was mainly to produce 2-MAG since usually more omega-3 PUFA is located at 2position of fish oil. ${ }^{6,8}$ 
One possible approach to obtain a dedicated fraction with different melting

2 points is the application of fractionation. There are several approaches available to

3 fractionate fats and oils including dry fractionation (without solvent), wet

4 fractionation (with solvent), and super-critical fluid fractionation. ${ }^{10,11}$ Using these

5 fractionation processes, lipid fractions with different nutritive properties can be

6 produced since the melting behavior of lipids is strongly related to the number of

7 double bonds, meaning PUFA fractions and their derivatives can have very different

8 melting properties from the rest fractions in the mixture.

Therefore, in this study, we designed the production of MAG rich in omega-3 PUFA (EPA and DHA) into a two-step operation. In the first step, an efficient glycerolysis system should be set up for the enzymatic production of MAG from fish oil. The system with tertiary alcohols was considered for the above consideration, as high yields of MAG can be expected in the system after optimization. ${ }^{2,5}$ Under such a possibility, the second step was targeted to fractionate the MAG containing PUFA. Normally, such MAG have much lower melting points than MAG containing saturated or monounsaturated fatty acids. Therefore, a physical fractionation system was also studied to isolate the omega-3 PUFA containing MAG from other MAG.

\section{MATERIALS}

Crude tuna oil from Skipjack tuna head, with water content of $4.4 \%$ and free fatty acid content of $0.36 \%$, was provided by Chotiwat Industrial Co. Ltd. (Hat Yai, Thailand). The oil was prepared from crude tuna oil by a conventional pressing method. The refined oil was achieved through degumming, neutralization, bleaching, and deodorizing. The major fatty acid compositions of the refined oil (wt $\%)$ was as following: C14:0, C16:0, C18:0, C18:1, C18:2, C20:5 and C22:6 (4.2, 30.6, 9.3, 17.3, 2.6, 6.7 and 29.0, respectively). The glycerol was analytical grade with $0.2 \%$ water. 
1 The properties of $\mathrm{TB}$ are boiling point $83{ }^{\circ} \mathrm{C}$, melting point $25^{\circ} \mathrm{C}$, relative density

2 (water=1) 0.8 , octanol/water partition coefficient $\left(\log P_{\mathrm{o} / \mathrm{w}}\right) 0.4$, and with colorless

3 appearance. Commercially immobilized lipase, Novozym 435, from Candida

4 antarctica lipase B, was obtained from Novozymes (Bagsvaerd, Denmark) and

5 Pseudomonas fluorescens lipase (Lipase AK) was a gift from Amano Pharmaceutical

6 Co. Ltd (Nagoya, Japan). Accurel EP-100, a microporous polypropylene powder

7 (particle size $<400 \mu \mathrm{m}$ ), was a gift from Akzo Nobel Membrana (Obernburg,

8 Germany). All other chemicals and solvents used were of reagent grade or analytical 9 grade.

\section{METHODS}

Preparation of the immobilized lipase

Accurel EP-100 (10 g) was added to $100 \mathrm{~mL}$ of buffer $(\mathrm{pH} 7)$ containing 100 $\mathrm{U} / \mathrm{mL}$ Lipase $\mathrm{AK}$ and the mixture was stirred with a magnetic bar at $100 \mathrm{rpm}$ for 30 min. Afterward, $100 \mathrm{ml}$ of $0.1 \mathrm{M}$ phosphate buffer $(\mathrm{pH} 7)$ was added and the suspension was filtered through a Buchner funnel by vacuum. The immobilized enzyme (IM-AK) was washed with $100 \mathrm{~mL}$ of $0.1 \mathrm{M}$ phosphate buffer to remove the unbound enzyme.

The water content of the immobilized enzyme was adjusted by different methods ${ }^{12}$. The first method was vacuum drying in a desiccator at room temperature for $12 \mathrm{~h}\left(\mathrm{a}_{\mathrm{w}}=0.389\right)$. The second method was acetone washing and evaporation $\left(a_{w}=0.019\right)$. And the last method was to equilibrate the enzyme over saturated LiCl solution in a desiccator at $25^{\circ} \mathrm{C}$ for $16 \mathrm{~h}\left(\mathrm{a}_{\mathrm{w}}=0.113\right)$. The water activity $\left(a_{w}\right)$ of the prepared enzymes was measured with an Aqualab Water Activity Meter (Decagon Devices, Inc., Washington, USA) at room temperature, as shown in the parenthesis. 
Enzymatic glycerolysis of tuna oil

The mixture of $10 \mathrm{~g}$ of tuna oil, required amount of glycerol and TB was incubated in a capped $25-\mathrm{mL}$ flask at the designed conditions on a $400 \mathrm{rpm}$ shaker. The reaction was initiated by the addition of lipases. At selected intervals, $0.25 \mathrm{~mL}$ of reaction mixture was withdrawn and the lipase was removed by filtration and the solvent was removed by vacuum. All samples were stored at $-20{ }^{\circ} \mathrm{C}$ before analysis. Experimental repeatability for batch reactions was conducted through three experiments under the following condition: temperature $45^{\circ} \mathrm{C}$, glycerol/tuna oil molar ratio 4.5:1.0, TB/tuna oil 2.2:1.0 (w/w), $15 \mathrm{wt} \%$ lipase (based on oil and glycerol), and no additional water.

\section{Fractionation of PUFA-MAG from reaction mixture of glycerolysis of tuna oil}

The product collected after reaction under the optimal conditions was subjected to solvent removal under vacuum and was named as crude MAG. The crude MAG in $0.1 \mathrm{~g}$ was dissolved in $30 \mathrm{~mL}$ of different solvents or mixtures. Acetone and hexane are commonly cited in the literature and used industrially. Therefore, these two solvents were selected together with one mixture between the two solvent in $50 / 50(\mathrm{v} / \mathrm{v})$. The fractionation was conducted under different temperatures. Based on melting points of different MAG fractions, the 10,4 , and $0{ }^{\circ} \mathrm{C}$ were selected for evaluation. The fractionation was conducted in a selected solvent and temperature for $3 \mathrm{~h}$. Afterwards the samples were centrifuged at the same temperature for $30 \mathrm{~min}$ at $10000 \mathrm{rpm}$. The supernatant was removed and the solid was washed several times with the same solvent cooled to the same temperature. The liquid parts were collected together. The solvent was removed form both solids and liquids by a vacuum evaporator. The two fractions were then weighed and used for further analysis. 
Analysis of acylglycerols by TLC-FID

The components of oil phase were analyzed with a thin-layer chromatography with flame ionization detector (TLC/FID)(IATROSCAN MK5, Iatron Laboratories Inc., Tokyo, Japan) for the content of TAG, 1,2(2,3)-DAG, 1,3-DAG, MAG and free fatty acids (FFA). ${ }^{13}$ The samples diluted in chloroform/methanol $(2: 1 \mathrm{v} / \mathrm{v})$ were spotted onto the chromarod and developed for $35 \mathrm{~min}$ in a mixture of benzene/chloroform/acetic acid (50:20:0.7, v/v/v). After developing and drying, the rods were subjected to scanning with FID. Standards were used to identify the peaks. The peaks areas were normalized and used for evaluation of reactions. Triplicate analysis was conducted and the averages were used.

\section{Analysis of fatty acids compositions}

The fatty acid compositions of acylglycerol species were determined by converting into fatty acids methyl esters followed by GC analysis. After evaporating excess solvent of the sample, the mixture was applied to normal silica gel TLC-plate and developed in benzene/chloroform/acetic acid (50:20:0.7, v/v/v). After drying, the MAG band was scraped off and methylated with $0.5 \% \mathrm{NaOH}$ in methanol (1000 $\mu \mathrm{L})$, for $10 \mathrm{~min}$ at $60{ }^{\circ} \mathrm{C}$. The methyl esters were extracted with $n$-hexane $(300 \mu \mathrm{L})$ for 1 min. The $n$-hexane layer was washed with $200 \mu \mathrm{L}$ distilled water and dried over anhydrous sodium sulfate. Analysis was carried out with a Perkin-Elmer Autosystem XL-GC gas chromatograph (Perkin-Elmer Corporation, Norwalk, CT) on a FFFAP column (PERMABOND-FFFAP DF-0.25, 25m×0.25mm i.d., MACHEREY-NAGEL, Germany). The carrier gas was helium at a flow rate of $0.5 \mathrm{~mL} / \mathrm{min}(15 \mathrm{psi})$ and operated in a split ratio of $50: 1$. The temperature was started from $150{ }^{\circ} \mathrm{C}$ for $0.50 \mathrm{~min}$ and increased at the rate of $4{ }^{\circ} \mathrm{C} / \mathrm{min}$ to $170{ }^{\circ} \mathrm{C}$, followed with the rate of $5{ }^{\circ} \mathrm{C} / \mathrm{min}$ to $195^{\circ} \mathrm{C}$, and further with the rate of $10^{\circ} \mathrm{C} / \mathrm{min}$ to and $215^{\circ} \mathrm{C}$ and held there for 14 
1 min. Injector and detector temperatures were $250{ }^{\circ} \mathrm{C}^{14}$ Response factors were

2 determined using a standard mixture of fatty acid methyl esters. Duplicate analyses

3 were carried out for all samples. The relative standard deviation was less than $4.1 \%$

4 for all results more than $10 \%$ and less than $6.6 \%$ for results less than $10 \%$.

$5 \quad$ Statistical analysis

6 The SPSS program analysis was used for data analysis. ${ }^{15}$ Analysis of variance

7 and t-test were used to evaluate the significance and difference of data. Values were

8 considered significant at $P<0.05$ level.

9 RESULTS AND DISCUSSION

\section{Selection of lipases for glycerolysis}

Enzyme characteristics can have determinant functions for the product development and process development. In recent progress of enzymatic production of MAG in solvent systems, Novozym 435 was recommended for the tertiary solvent system. ${ }^{2,5}$ Kaewthong and H-Kittikun ${ }^{13}$, however, concluded from a solvent screening that IM-AK showed good activity in the system used. To find an appropriate catalyst for the aimed MAG processing, the two immobilized lipases concluded from the above studies were selected for further evaluation, i.e. Novozym 435 from Candida antarctica B lipase (nonspecific) with the hydrolytic activity of $9.8 \mathrm{U} / \mathrm{mg}$ immobilized enzyme and IM-AK from Pseudomonas fluorescens lipase (1,3-specific lipase) with the hydrolytic activity of $0.97 \mathrm{U} / \mathrm{mg}$ immobilized enzyme. In the TB and hexane media, experiments were conducted at the ratio of organic solvent to tuna oil 2.2:1.0 (w/w), immobilized enzyme $100 \mathrm{U} / \mathrm{g}$ (based on total substrates), 4.5:1.0 (mol/mol) glycerol/tuna oil, $45^{\circ} \mathrm{C}$, and reaction time of $8 \mathrm{~h}$. The results showed that the reaction by both enzymes in hexane was slow with very low TAG conversion (less than 20\%), while in TB much more MAG were formed (data not shown). In TB, 
1 Novozym 435 showed the highest activity with 90\% yield of MAG, while IM-AK

2 gave $70 \%$ conversion but with $21 \%$ FFA (Fig. 1). High FFA content is a problem for

3 industrial applications. It obviously came from the higher water content in the

4 immobilized lipase. We therefore studied the pretreatment of the IM-AK to see if the

5 performance could be further improved because it could be a cheaper alternative to

6 Novozym 435. Therefore, the IM-AK was pre-treated to reduce the water content and

7 the following different water activities $\left(a_{w}\right)$ were obtained as $0.369,0.113$, and 0.019 .

8 As seen from Fig. 2, once water content was down, the activity of the immobilized

9 enzyme was decreased as well, meaning the enzyme was water dependent. This

10 implies that the lipase needs higher amount of water to maintain the activity, but such

11 a high amount of water will consequently lead to the stronger hydrolysis reaction so

12 as to form higher amount of FFA. This behavior makes difficult for the use of IM-AK

13 in such reactions where polar solvents are used to exert stronger water partitioning

14 from enzymes. Therefore we conclude that IM-AK is not quite suitable for the

15 reaction system even though quite good reaction conversion can be obtained in high

16 water content situations (Fig. 1). As widely demonstrated and also proved in this

17 study, Novozym 435 has less water dependence and its catalytic activity did not drop

18 even in very polar systems with ethanol. ${ }^{2,5,16}$ After all, Novozym 435 was selected for

19 further process studies, even though it is a costly commercial lipase. With its low

20 water requirement, the process can have high benefit, in which a very low FFA

21 content can be obtained in the products. This is a very important issue for industrial

22 applications since higher FFA content will lead to the loss of oils as well as difficulty

23 in processing. 
Evaluations of solvent mixtures for glycerolysis of tuna oil

As demonstrated in a few recent publications, ${ }^{2,5}$ tertiary alcohols are suitable solvents for the efficient glycerolysis system with very short reaction time but high MAG yields. However, TB is solid in room temperature (melting point $25-26^{\circ} \mathrm{C}$ ) so as making the process operation difficult while TP is much more expensive (2-3 fold higher than TB). Therefore, a mixture could be a better choice for practical and costeffective processes. Therefore the mixtures of the two solvents as well as the mixtures with hexane were evaluated for the reaction system to offer possibilities for different selections. The glycerolysis reaction was carried out in such solvent mixtures and their results are shown in Fig. 3. Tertiary alcohols and their mixtures generally gave higher yields of MAG, even though there were slightly differences between each other. The mixtures of tertiary alcohols with low amount of hexane (20\%) also gave reasonably good result, but higher amount of hexane led to lower yields of MAG. Yields of MAG 90-95\% were occurred in mixtures of TB/hexane (down to 20\% v/v hexane) and TB/TP in various ratios $(20: 80,50: 50$, and 80:20 v/v). This offers a variety of possibilities of solvent selection in practical uses. As seen from the studies of the different mixtures, particularly with tertiary alcohols, the reaction behavior is very similar each other in terms of reaction conversion and enzyme activity (Fig. 3 and data not shown). In practical uses, different decisions can be made depending on the easiness of the process and cost of the solvents as well as other subjective considerations. To simplify the study for the fractionation part, TB was selected for the following experiments since more information has been accumulated in large scale operations concerning TB evaporation procedures and its safety approval from the authority. 


\section{Evaluations of other parameters on the MAG yield}

Various parameters for the reaction systems have been already evaluated in the early studies ${ }^{2,5}$. Due to the use of tuna oil where contains high content of DHA and EPA in this study, we had concerns whether the reaction will be seriously affected since the early work used the linoleic acid dominated sunflower oil as materials $\mathrm{s}^{2,5}$. Therefore, we still made the evaluation of various parameters. After all, the effects of parameters with the use of tuna oil were very similar to those pervious studies (data not shown). Therefore only a general summary is given below. The effects of enzyme loading, amount of solvent, substrate ratio and temperature on the glycerolysis of tuna oil were performed. In the batch reactions, $15 \mathrm{wt} \%$ Novozym 435 based on total substrates (glycerol and oil) gave the maximum reaction performance and was used for further reactions. The weight ratio of TB to tuna oil of 2.0:1.0-2.5:1.0 showed high MAG production with no significant difference. Therefore, the weight ratio of TB to tuna oil of 2.0:1.0 was selected. For the effect of glycerol amount, the result showed that the molar substrate ratio of glycerol and oil of 4.0:1.0-4.5:1.0 had no significant difference on MAG production. Therefore, in this study, 4.0:1.0 ( $\mathrm{mol} / \mathrm{mol})$ glycerol/tuna oil was decided. For the effect of temperature, glycerolysis of tuna oil was carried out at 30 to $50{ }^{\circ} \mathrm{C}$ and the results showed that the temperature of $40-50{ }^{\circ} \mathrm{C}$ showed high MAG production with no significant difference. Therefore, the temperature of $40{ }^{\circ} \mathrm{C}$ was selected for the production since lower temperature was recommended with respect to the product quality.

\section{MAG production under optimal conditions}

The recommended conditions for MAG production were finalized as using TB as the medium, the molar ratio of glycerol to tuna oil of 4.0:1.0, the weight ratio of TB to tuna oil with 2.0:1.0, using $15 \mathrm{wt} \%$ Novozym 435 (based on glycerol and tuna oil), 
and no additional water. The temperature was controlled at $40{ }^{\circ} \mathrm{C}$. Under these conditions, the yield of MAG of $90.8 \mathrm{wt} \%$ was obtained after $3 \mathrm{~h}$ incubation and the remained TAG was only $5.5 \mathrm{wt} \%$. A time course under such production conditions is also conducted (Fig. 4).

The major fatty acid compositions of the MAG fraction after separating by thin layer chromatography were determined by gas chromatography as follows: C14:0, C16:0, C18:1, C18:2, C20:5 and C22:6 (3.5, 29.7, 8.6, 17.1, 3.6, 6.3 and 30.5 $\mathrm{wt} \%$, respectively). The fatty acid compositions had no significant difference from that of the original tuna oil. The result indicated that the reaction gave little fatty acid selectivity for the formation of MAG. This is a reasonable conclusion since the reaction was an interesterification process where positional and fatty acid selectivity of the lipase will place no difference for the product formation.

\section{Fractionation of the reaction mixture from glycerolysis of tuna oil}

Temperature fractionation of fats or oils or their derivatives can be regarded as a thermo-mechanical separation process and has been widely used in industry. Individual species (for example TAG or MAG) for a given material are selectively crystallized from the liquid phase at different temperatures. During cooling of the liquid oil or melted material, the species with the highest melting point preferentially crystallized, resulting in solid phase within the system. For natural fats and oils, they are mostly complex mixtures of individual TAG that can contain from one to three different fatty acyl residues on their glycerol backbone. Because of this there is the large variation in the melting points of the TAG species, which complicates the fractionation process. ${ }^{10,11}$ For MAG product, single fatty acid residue is attached to glycerol backbone, the melting point profile is largely dependent on the fatty acids attached. Therefore, a simple separation of MAG with different fatty acids having 
1 different unsaturation is theoretically possible. In particular, EPA and DHA have 5-6

2 double bonds, the melting points of their MAG will be largely different from rest of

3 fatty acids in tuna oil. For this reason, a fractionation system with solvent used (so-

4 called wet fractionation) was studied.

5 Temperature is a critical issue for fractionation. Theoretically, MAG with

$6 \mathrm{C} 16: 0$ to $\mathrm{C} 18: 0$ have a melting point $(\mathrm{mp})$ in the range between $69-75^{\circ} \mathrm{C}$ under pure

7 lipid phase. ${ }^{11}$ The $\mathrm{C} 18: 1$ based MAG has a mp around $24{ }^{\circ} \mathrm{C}$ and $\mathrm{C} 18: 2$ based MAG

8 around $9{ }^{\circ} \mathrm{C}$. No information for the mp of EPA and DHA based MAG, but a melting

9 point much lower can be expected. Once solvent applied, the melting behavior is 10 completely different from pure lipid phase. Both solvent and concentration in the 11 solvent can have effect on the crystallization temperatures. Based on application of wet fractionation in industry as well as literature, ${ }^{11}$ three temperatures $\left(0,4,10{ }^{\circ} \mathrm{C}\right)$ were selected for this study.

Solvent is another issue. Acetone and hexane have been commonly applied in industry and many previous studies. Considering the higher polarity of the material, 16 the polarity of solvent may have effects on the fractionation process. Therefore, both solvents were selected for further evaluation including their mixtures.

The effects of solvent and temperature on yield and fatty acid compositions were evaluated. Table 1 shows that percentage of EPA and DHA were higher in liquid fraction than solid fraction. The yield of liquid fraction was decreasing in general with the decreasing of temperature. Consequently, the EPA and DHA content in the MAG of the liquid fraction was increasing. The effect of solvent mixing was not very significant. There was a tendency that better fractionation was obtained in the acetone system than in the hexane system. Yang et al. ${ }^{17}$ found that the percentage of saturated fatty acid of stearin decreased with increasing solvent polarity, and percentage of EPA 
1 and DHA increased with solvent polarity and fractionation temperature. Lee and

2 Foglia $^{11}$ also reported that fractionation with acetone at low temperature was effective

3 for enriching the monounsaturated fatty acid of chicken fat in the liquid fraction.

4 Yokochi et al. ${ }^{18}$ reported that the winterization process with acetone at $-20{ }^{\circ} \mathrm{C}$ showed

5 higher separation efficiency for tri-unsaturated TAG into liquid fraction than the other 6 solvents.

In general, C16:0 and C18:0 were dramatically reduced in the liquid fraction and increased in the solid fraction. ${ }^{11,12}$ The oleic acid was also changing but not highly consistent. The crystallization of oleic acid based MAG may need further lower temperature. As commonly known, the yield of the liquid fraction will be reduced with the decreasing of the temperature. The loss of the liquid fraction which is trapped by the solids, will also increase. With the present set-up, a liquid fraction with around $50 \%$ yield of MAG contained $70 \%$ EPA and DHA at $0{ }^{\circ} \mathrm{C}$ using acetone was obtained.

\section{CONCLUSION}

Physicoenzymatic production of MAG containing PUFA especially EPA and DHA was investigated. A few solvent mixtures were suitable for production of MAG by using Novozym 435 as a catalyst in glycerolysis of tuna oil. A few reaction parameters have been evaluated including solvent amount, substrate ratio, enzyme load, and temperature. The yield of MAG up to $90.8 \%$ could be achieved with suitable conditions. The temperature fractionation under different solvents was evaluated in order to produce a fraction with higher content of EPA and DHA. Temperature was a critical parameter for effective fractionation. A liquid fraction under $0{ }^{\circ} \mathrm{C}$ fractionation could be obtained with around 70\% EPA and DHA and in a yield of 
1 MAG around $50 \%$. A possibility of enriching the EPA and DHA into MAG has been

2 built.

\section{ACKNOWLEDGEMENTS}

The research support by the Royal Golden Jubilee Program (RGJ, Thailand) is gratefully acknowledged. The authors would like to thank Chotiwat Industrial Co. Ltd. (Hat Yai, Thailand) for providing crude tuna oil, Amano (Nagoya, Japan) for Lipase AK and Novozymes (Bagsvaerd, Denmark) for Novozym 435, as well as, Akzo Nobel Membrana for Accurel EP-100.

\section{REFERENCES}

1 Bornscheuer UT, Lipase-catalyzed synthesis of monoacylglycerols. Enzyme Microb Technol 17:578-586 (1995).

2 Damstrup ML, Jensen T, Sparsø FV, Kiil SZ, Jensen AD and Xu X, Solvent optimization for efficient enzymatic monoacylglycerol production based on a glycerolysis reaction. J Am Oil Chem Soc 82:559-564 (2005).

3 Wehtje E, Adlercreutz P, Water activity and substrate concentration effects on lipase activity. Biotechnol Bioeng 55:798-806 (1997).

4 Peng $\mathrm{L}, \mathrm{Xu} \mathrm{X}$ and Tan $\mathrm{T}$, Enzymatic production of high quality of monoacylglycerols, in Research Advances in Oil Chemistry, ed. By Mohan RM. GRN, Calcutta, India, pp 53-78 (2000).

5 Yang $\mathrm{T}$, Rebsdorf $\mathrm{M}$, Engelrud $\mathrm{U}$ and $\mathrm{Xu} \mathrm{X}$, Enzymatic production of monoacylglycerols containing polyunsaturated fatty acids through an efficient glycerolysis system. J Agric Food Chem 53:1475-1481 (2005).

6 Narayan B, Miyashita K And Hosakawa M, Physiological effects of eicosapentaenoic acid (EPA) and docosahexaenoic acid (DHA)- A review. Food Rev Int 22:291-307 (2006). 
17 Ruxton CHS, Reed SC, Simpson MJA and Millington KL, The health benefits of omega-3 polyunsaturated fatty acids: a review of the evidence. $J$ Human Nutr Dietet 17:449-459 (2004). transesterification of tuna oil to enriched omega-3 polyunsaturated fatty acids. Food Chem 87:415-421 (2004).

9 Wongsakul S, Prasertsan P, Bornscheuer UT and H-Kittikun A, Synthesis of 2monoglycerides by alcoholysis of palm oil and tuna oil using immobilized

10 Lee KT and Foglia TA, Fractionation of chicken fat triacylglycerols: synthesis of structures lipids with immobilized lipases. J Food Sci 65:826-831 (2000). lipases. Eur J Lipid Sci Technol 105:68-73 (2003).

11 Lee KT, Foglia TA and Oh, MJ, Lipase-catalyzed synthesis of structured lipids with fatty acids fractionated from saponified chicken fat and menhaden oil. Eur J Lipid Sci Technol 103:777-772 (2001).

12 Lee SY and Rhee JS, Production and partial purification of lipase from Pseudomonas putida 3SK. Enzyme Microb Technol 15:617-623 (1993).

13 Kaewthong W and H-Kittikun A, Glycerolysis of palm olein by immobilized lipase PS in organic solvents. Enzyme Microb Technol 35:218-222 (2004).

14 Joseph JD and Ackman, Capillary column gas chromatographic method for analysis of encapsulated fish oil and fish oil ethyl ester: collaborative study. $J$ AOAC Int 75:488-506 (1992).

15 SPSS, SPSS for window. Release 11.0.0 (19 Sept. 2001), standard version. SPSS Institute, Cary, NC (1989-2001). 
116 Piyatheerawong W, Iwasaki Y, Xu X and Yamane T, Dependency of water concentration on ethanolysis of trioleoylglycerol by lipases. J Mol Catal B-Enz 28:19-24 (2004).

417 Yang $\mathrm{MH}$, Chang $\mathrm{CC}$ and Chen $\mathrm{RH}$, Effect of solvent polarity and fractionation 5 temperature on the physicochemical properties of squid viscera stearin. $J A m$ Oil Chem Soc 69:1192-1197 (1992).

18 Yokochi T, Usita M T, Kamisaka Y, Nakahara T and Suzuki O, Increase in the $\gamma$ linolenic acid content by solvent winterization of fungal oil extracted from Mortierella Genus. J Am Oil Chem Soc 67:846-851 (1990). 
1 Table 1. Effect of solvents ratios $^{\mathrm{a}}$ and temperatures on the major fatty acid

2 compositions of monoacylglycerol fractions.

\begin{tabular}{|c|c|c|c|c|c|c|c|c|c|c|}
\hline \multirow{2}{*}{$\begin{array}{l}\text { Temperature } \\
\left({ }^{\circ} \mathrm{C}\right)\end{array}$} & \multirow{2}{*}{$\begin{array}{l}\text { Solvent mixture } \\
\text { (hexane /acetone, } \\
\mathrm{v} / \mathrm{v} \text { ) }\end{array}$} & \multirow{2}{*}{\multicolumn{2}{|c|}{$\begin{array}{l}\text { Yield of liquid } \\
\text { and solid } \\
\text { fractions } \\
(\mathrm{wt} \%)^{\mathrm{b}}\end{array}$}} & \multicolumn{7}{|c|}{ Major fatty acid content (wt\%) } \\
\hline & & & & $\mathrm{C} 14: 0$ & C16:0 & C18:0 & C18:1 & C18:2 & C20:5 & C22:6 \\
\hline \multirow[t]{6}{*}{10} & \multirow[t]{2}{*}{$100 / 0$} & $\mathrm{~L}$ & 84.9 & 2.9 & 30.3 & 8.3 & 17.1 & 3.7 & 4.9 & 30.9 \\
\hline & & $\mathrm{S}$ & 15.1 & 6.6 & 38.6 & 16.6 & 14.6 & 0.7 & 10.1 & 10.3 \\
\hline & \multirow[t]{2}{*}{$50 / 50$} & $\mathrm{~L}$ & 69.8 & 3.7 & 23.3 & 5.0 & 20.2 & 3.0 & 7.0 & 37.4 \\
\hline & & $\mathrm{S}$ & 30.2 & 2.7 & 45.1 & 15.3 & 24.8 & 3.7 & 2.7 & 5.5 \\
\hline & \multirow[t]{2}{*}{$0 / 100$} & $\mathrm{~L}$ & 63.1 & 3.9 & 15.2 & 3.2 & 16.9 & 4.2 & 7.3 & 47.5 \\
\hline & & $\mathrm{S}$ & 36.9 & 1.6 & 49.2 & 15.6 & 20.3 & 3.3 & 3.9 & 5.5 \\
\hline \multirow[t]{6}{*}{4} & \multirow[t]{2}{*}{$100 / 0$} & $\mathrm{~L}$ & 67.9 & 2.5 & 13.2 & 4.0 & 21.1 & 4.0 & 5.6 & 48.6 \\
\hline & & $\mathrm{S}$ & 32.1 & 6.7 & 61.5 & 21.2 & 4.5 & 0.5 & 2.2 & 1.8 \\
\hline & \multirow[t]{2}{*}{$50 / 50$} & $\mathrm{~L}$ & 71.6 & 2.2 & 15.4 & 4.6 & 19.8 & 4.1 & 5.9 & 46.3 \\
\hline & & $\mathrm{S}$ & 28.4 & 6.7 & 66.4 & 16.6 & 4.7 & 1.1 & 1.4 & 2.2 \\
\hline & \multirow[t]{2}{*}{$0 / 100$} & $\mathrm{~L}$ & 65.3 & 3 & 4.9 & 3.5 & 22.4 & 6.2 & 8.5 & 50.3 \\
\hline & & $\mathrm{S}$ & 44.7 & 3.9 & 72.3 & 13.8 & 3.2 & 0.4 & 3.1 & 1.2 \\
\hline \multirow[t]{6}{*}{0} & \multirow[t]{2}{*}{$100 / 0$} & $\mathrm{~L}$ & 52.8 & 1.7 & 4.2 & 0.3 & 23.7 & 5.1 & 8.0 & 56.0 \\
\hline & & $\mathrm{S}$ & 47.2 & 4.2 & 66.3 & 17.2 & 7.7 & 0.1 & 2.0 & 1.8 \\
\hline & \multirow[t]{2}{*}{$50 / 50$} & $\mathrm{~L}$ & 50.6 & 1.9 & 0.3 & 0.4 & 20.8 & 4.9 & 8.6 & 60.5 \\
\hline & & $\mathrm{S}$ & 49.4 & 4.3 & 60.5 & 19.3 & 12.3 & 0.8 & 1.3 & 0.9 \\
\hline & \multirow[t]{2}{*}{$0 / 100$} & $\mathrm{~L}$ & 47.5 & 1.4 & 0.4 & 0.4 & 18.6 & 6.3 & 10.1 & 61.2 \\
\hline & & $\mathrm{S}$ & 52.5 & 5.3 & 54.6 & 14.9 & 15.6 & 0.4 & 1.8 & 5.3 \\
\hline
\end{tabular}

3

$4{ }^{\mathrm{a}} \mathrm{MAG} /$ solvent mixture, 1:30 (v/v): fractionation conditions: $3 \mathrm{~h}$ at designated

5 temperature after rapid cooling from room temperature; fraction temperature were 10 ,

$6 \quad 4$ and $0{ }^{\circ} \mathrm{C}$.

$7{ }^{b}{ } t_{0}$ recovery of liquid and solid fractions at the same temperature. L-liquid

8 fraction; S-solid fraction.

9 


\section{FIGURE CAPTIONS:}

Fig. 1. Glycerolysis time courses of tuna oil in tert-butanol. Reaction conditions: temperature $45^{\circ} \mathrm{C}$, glycerol/tuna oil molar ratio $4.5: 1.0$, tert-butanol/tuna oil 2.2:1.0 (wt/wt), $15 \mathrm{wt} \%$ lipases (based on total substrates), and no additional water. Abbreviations: TAG (triacylglycerol), DAG (diacylglycerol), MAG (monoacylglycerol), FFA (free fatty acid), AK (Immobilized lipase AK), 435 (Novozym 435)

Fig. 2. Glycerolysis time courses of tuna oil in tert-butanol by immobilized lipase AK (a). dry with acetone (b) adjusted water content with $\mathrm{a}_{\mathrm{W}}=0.113$ by saturated salt $(\mathrm{LiCl})(\mathrm{c})$. dry in vacuum. Reaction conditions: temperature 45 ${ }^{\circ} \mathrm{C}$, glycerol/oil molar ratio 4.5:1.0, tert-butanol/oil 2.2:1.0 (w/w), $15 \mathrm{wt} \%$ Immobilized Lipase AK (based total substrates) and no additional water. See Fig. 1 for abbreviations.

Fig. 3. Effects of solvent mixtures on glycerolysis of tuna oil. Reaction conditions: temperature $45^{\circ} \mathrm{C}$, glycerol/tuna oil molar ratio $4.5: 1.0$, reaction time $3 \mathrm{~h}$, $15 \mathrm{wt} \%$ Novozym 435 (based on total substrates) and no additional water.

Fig. 4. Time course of glycerolysis by Novozym 435 in TB. The reaction mixture contained the mole ratio of glycerol to tuna oil with 4.0:1.0, the weight ratio of TB to tuna oil with 2.0:1.0, reaction time $3 \mathrm{~h}, 15 \mathrm{wt} \%$ Novozym 435 (based on glycerol and tuna oil) and no additional water. 
$1 \quad$ Fig. 1

2

3

4

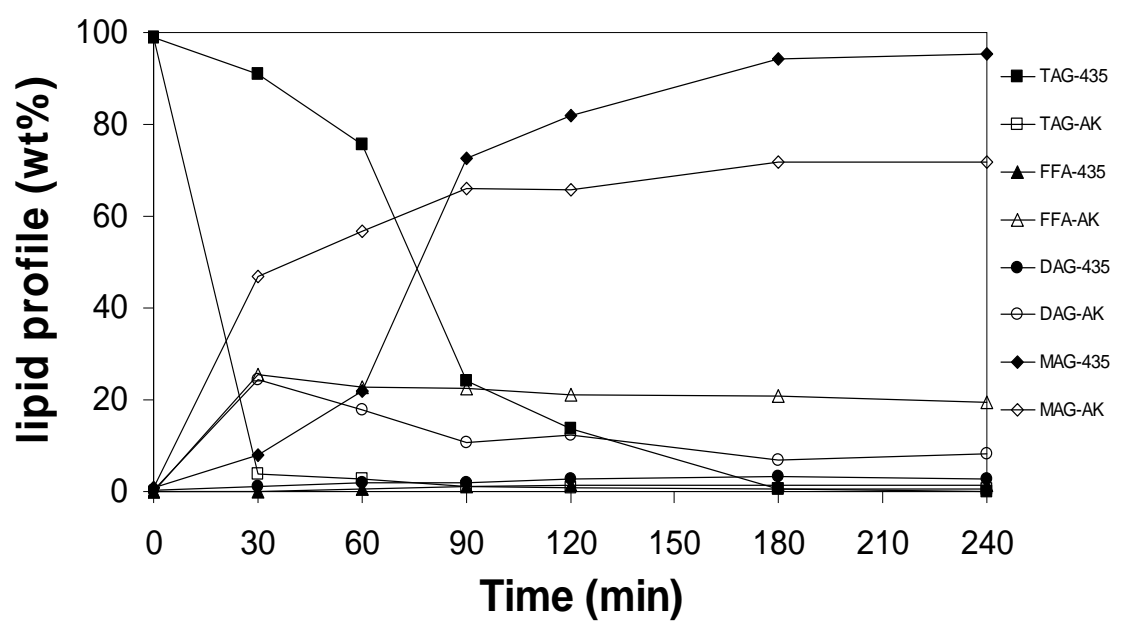

5

6

7

8

9

10

11

12

13

14

15

16

17

18 
Fig. 2

2

3

4

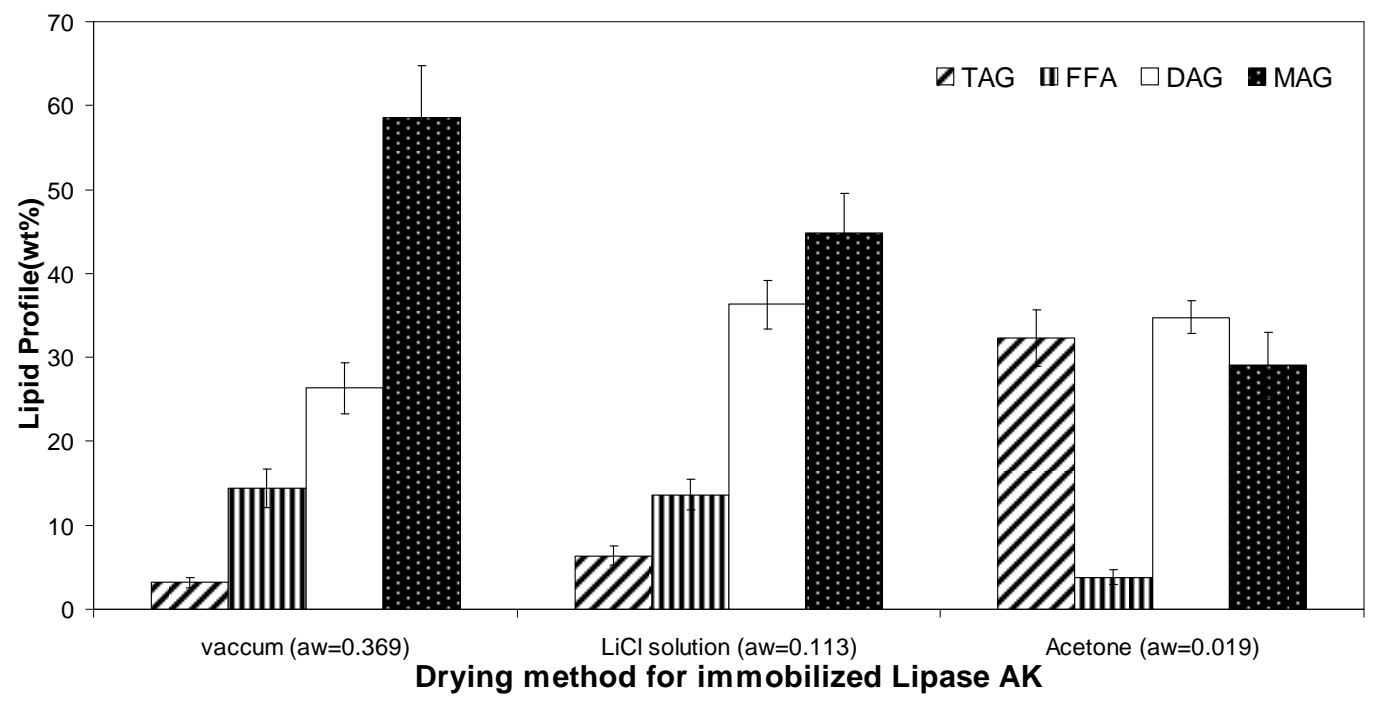

5

6

7

8

9

10

11

12

13

14

15

16

17

18 


\section{$1 \quad$ Fig. 3}

2

3

4

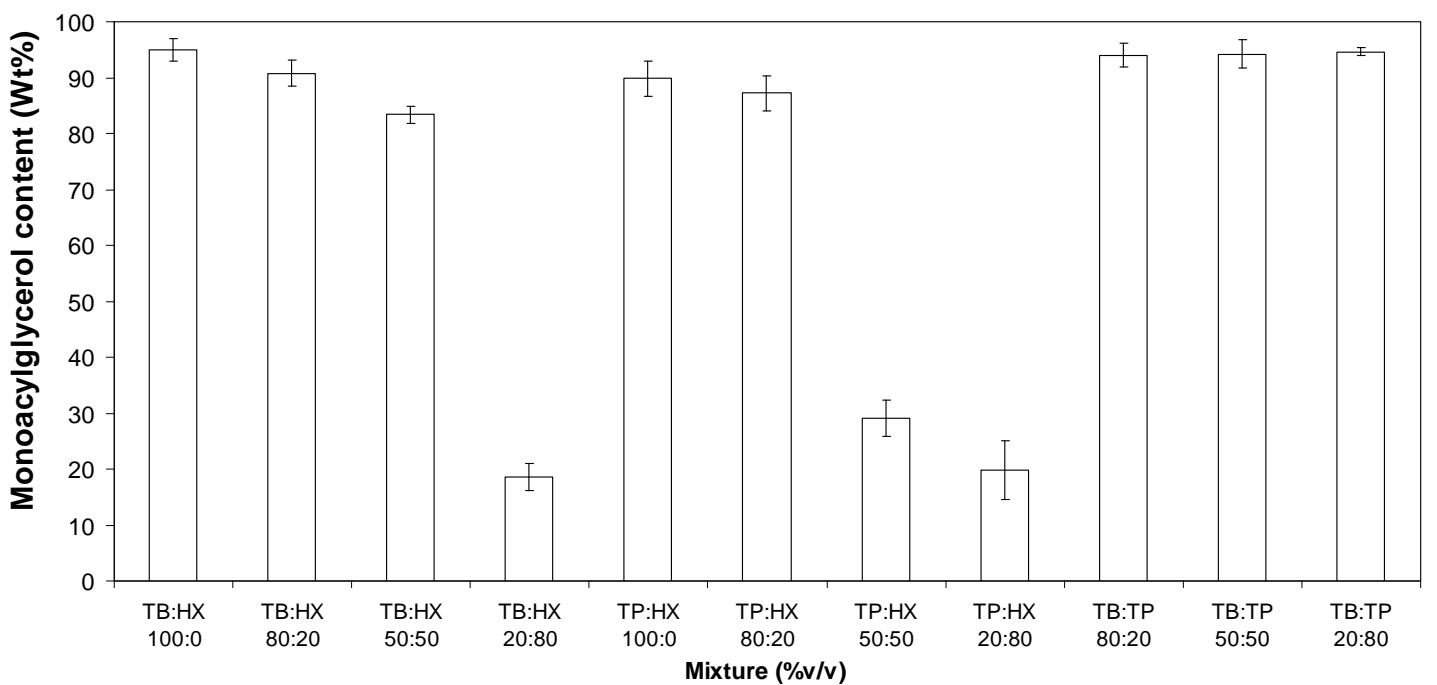

5

6

7

8

9

10

11

12

13

14

15

16

17

18 
1 Fig. 4

2

3

4

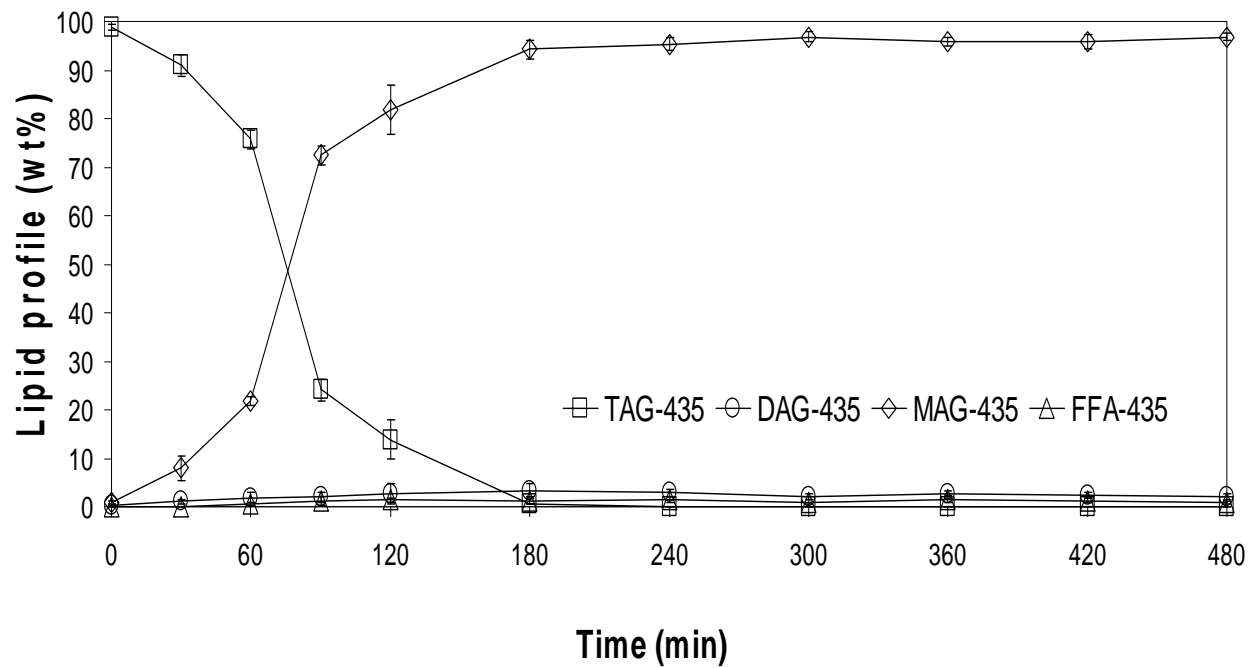

5 